
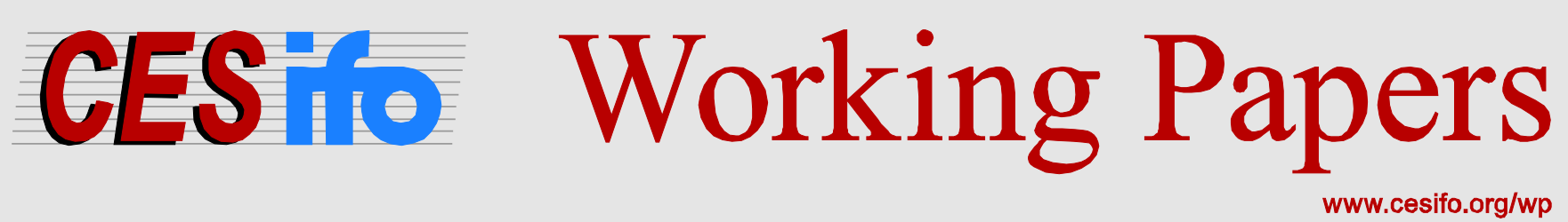

\title{
Why Firms Should Care for all Consumers
}

\author{
Lisa Planer-Friedrich \\ Marco Sahm
}

CESIFO WORKING PAPER NO. 5612

CATEGORY 11: INDUSTRIAL ORGANISATION

NOVEMBER 2015

An electronic version of the paper may be downloaded

- from the SSRN website:

- from the RePEc website:

- from the CESifo website: WWW.SSRN.com

www.RePEc.org

www.CESifo-group.org/wp 


\title{
Why Firms Should Care for all Consumers
}

\begin{abstract}
We compare the strategic potential of Corporate Social Responsibility and Customer Orientation as commitments to larger quantities in Cournot competition. In addition to profits, firms can choose to care for the surplus of either all consumers (CSR) or their own customers only (CO), and if so, to what extent. We find that firms prefer to care for all consumers, choosing positive levels of CSR.
\end{abstract}

JEL-Codes: D430, L130, L210.

Keywords: Corporate Social Responsibility, Customer Orientation, Cournot duopoly, commitment.

\author{
Lisa Planer-Friedrich \\ Department of Economics \\ Otto-Friedrich-University \\ Feldkirchenstrasse 21 \\ Germany - 96052 Bamberg \\ lisa.planer-friedrich@uni-bamberg.de
}

\author{
Marco Sahm \\ Department of Economics \\ Otto-Friedrich-University \\ Feldkirchenstrasse 21 \\ Germany - 96052 Bamberg \\ marco.sahm@uni-bamberg.de
}




\section{Introduction}

Many authors have argued that firms benefit from taking the needs and wishes of their buyers into account (e.g. Deshpandé et al., 1993). Königstein and Müller (2001) model so-called Customer Orientation (CO) in a simple way, including the weighted surplus of its own customers into the objective function of a firm. They show that $\mathrm{CO}$ will outperform pure profit maximization in Cournot competition, because it enables firms to commit to larger quantities.

A more general approach in corporate culture is Corporate Social Responsibility (CSR). It refers to all social and environmentally friendly activities of a firm beyond its legal requirements (Kitzmueller and Shimshack, 2012). Goering (2008), Kopel et al. (2014), and Planer-Friedrich and Sahm (2015) focus on a narrower notion of CSR where the social engagement of firms is directed only towards consumers. Including the weighted surplus of all consumers rather than that of its own customers only into the objective function of a firm, their notion of CSR is still wider than that of CO by Königstein and Müller (2001). Just as CO, CSR serves as a commitment to larger quantities in Cournot competition, and thus yields a strategic advantage over pure profit maximizing rivals (Kopel et al., 2014, Planer-Friedrich and Sahm, 2015).

In this paper, we compare the strategic potential of CSR and CO as commitments to larger quantities in Cournot competition. In particular, we address the question whether firms prefer to care for all consumers or their own customers only. To this end, we consider a duopoly market for some homogeneous good with linear demand and constant marginal costs. We stick to the standard assumption of profit maximization but model competition between the two symmetric firms as a three-stage game. First, the firms simultaneously determine their corporate culture, choosing either CSR or CO. Second, the firms simultaneously specify the extent of engagement into $\mathrm{CSR} / \mathrm{CO}$, hiring an executive who is known to have an appropriate concern. Finally, the firms' executives simultaneously decide upon output in order to maximize their objective functions.

Solving the game by backward induction for its subgame perfect equilibrium (SPE), we find that both firms choose CSR as their corporate culture, putting positive weight on the surplus of all consumers. In this sense, CSR outperforms CO. To gain some intuition, note that the surplus of all consumers includes the surplus of the firm's own customers, both being increasing and convex functions of the firm's output. The socially responsible firm thus derives, ceteris paribus, a larger marginal benefit from its output. This implies that CSR provides stronger commitment to large quantities than CO. 


\section{The Model}

We consider Cournot competition between two profit maximizing firms on the market for some homogeneous good with normalized linear inverse demand $p=1-\left(q_{1}+q_{2}\right)$, where $p$ denotes the price of the good and $q_{i}$ denotes the output of firm $i \in\{1,2\}$. For simplicity, we assume zero marginal costs of production. Duopoly competition is modeled as a three-stage game $\Gamma$.

In the first stage, the firms simultaneously take the fundamental decision on their corporate culture to be either socially responsible, indexed by $S$, or customer oriented, indexed by $C$. This choice can be thought of as signing an appropriate corporate charter. Formally, CSR differs from CO in the respective objective function $V_{i}$ : In addition to profits $\pi_{i}$, the former contains the surplus of all consumers, denoted by $C S$ (Kopel et al., 2014), whereas the latter only contains the surplus of the firm's own customers, denoted by $C_{i}$ (Königstein and Müller, 2001), i.e.

$$
\begin{aligned}
& V_{i}^{S}=\pi_{i}+\theta_{i}^{S} \cdot C S=\left[1-\left(q_{i}+q_{j}\right)\right] q_{i}+\frac{1}{2} \cdot \theta_{i}^{S} \cdot\left(q_{i}+q_{j}\right)^{2}, \\
& V_{i}^{C}=\pi_{i}+\theta_{i}^{C} \cdot C_{i}=\left[1-\left(q_{i}+q_{j}\right)\right] q_{i}+\frac{1}{2} \cdot \theta_{i}^{C} \cdot q_{i}^{2} .
\end{aligned}
$$

In the second stage, the firms simultaneously choose their level of CSR or CO, i.e. the weight $\theta_{i}^{S} \geq 0$ or $\theta_{i}^{C} \geq 0$ they put on consumer surplus $C S$ or customer surplus $C_{i}$. This could be realized by hiring an executive manager with appropriate preferences, known as strategic delegation (see e.g. Fershtman and Judd, 1987). Allowing for zero weights, our model includes the ordinary case of pure profit maximization. In the third stage, firms' executives decide simultaneously on their output levels $q_{i} \geq 0$ in order to maximize their objective functions $V_{i}$.

\section{Analysis}

We solve game $\Gamma$ by backward induction for its SPE. To this end, we distinguish the three different constellations that may arise after the first stage.

\subsection{Competition between two CSR firms}

First suppose that both firms have chosen CSR as corporate culture at the first stage and each firm $i \in\{1,2\}$ has chosen its CSR level $\theta_{i}^{S}$ at the second stage. At the third stage, firm $i$ chooses its output $q_{i}$ in order to maximize 
its objective function (1) for any given weight $\theta_{j}^{S}$ of the rival firm. From the first-order condition $\partial V_{i}^{S} / \partial q_{i}=0$ we derive firm $i$ 's best response:

$$
q_{i}\left(q_{j}\right)=\frac{1-\left(1-\theta_{i}^{S}\right) q_{j}}{\left(2-\theta_{i}^{S}\right)} .
$$

Using the symmetry of firms, we compute the equilibrium quantity of firm $i \in\{1,2\}$ as a function of $\theta_{i}^{S}$ and $\theta_{j}^{S}$ :

$$
q_{i}=\frac{1+\theta_{i}^{S}-\theta_{j}^{S}}{3-\left(\theta_{i}^{S}+\theta_{j}^{S}\right)} .
$$

At the second stage, each firm anticipates these quantities and the corresponding price and chooses the CSR level $\theta_{i}^{S}$ in order to maximize the corresponding profit

$$
\pi_{i}=\left[1-\left(q_{i}+q_{j}\right)\right] q_{i}=\frac{\left(1-\theta_{j}^{S}\right)^{2}-\left(\theta_{i}^{S}\right)^{2}}{\left(3-\theta_{i}^{S}-\theta_{j}^{S}\right)^{2}} .
$$

The first-order condition $\partial \pi_{i} / \partial \theta_{i}^{S}=0$ yields the best response

$$
\theta_{i}^{S}\left(\theta_{j}^{S}\right)=\frac{\left(1-\theta_{j}^{S}\right)^{2}}{3-\theta_{j}^{S}} .
$$

Again using the symmetry of firms, we compute the equilibrium weights on consumer surplus $\theta_{i}^{S}=\theta^{S S}:=(5-\sqrt{17}) / 4 \approx 0.219$ as well as the corresponding quantities $q_{i}=q^{S S} \approx 0.3903$ and profits $\pi_{i}=\pi^{S S} \approx 0.0856$ for $i \in\{1,2\}$.

\subsection{Competition between one CSR firm and one CO firm}

Now suppose that one firm, $S$, has chosen CSR, whereas the other firm, $C$, has chosen $\mathrm{CO}$ as corporate culture at the first stage. Further suppose that each firm $i \in\{S, C\}$ has chosen its weight $\theta^{i}$ at the second stage. At the third stage, firm $i \in\{S, C\}$ chooses its output $q^{i}$ in order to maximize its objective function $V^{i}$ for any given weight $\theta^{j}$ of firm $j \neq i$, where $V^{S}$ and $V^{C}$ are given by (1) and (2). From the first-order conditions $\partial V^{i} / \partial q^{i}=0$ we derive the best response functions

$$
q^{S}\left(q^{C}\right)=\frac{1-\left(1-\theta^{S}\right) q^{C}}{2-\theta^{S}} \quad \text { and } \quad q^{C}\left(q^{S}\right)=\frac{1-q^{S}}{2-\theta^{C}}
$$

Solving for the equilibrium quantities as functions of $\theta^{S}$ and $\theta^{C}$ yields

$$
q^{S}=\frac{1-\theta^{C}+\theta^{S}}{3-2 \theta^{C}-\theta^{S}+\theta^{S} \theta^{C}} \quad \text { and } \quad q^{C}=\frac{1-\theta^{S}}{3-2 \theta^{C}-\theta^{S}+\theta^{S} \theta^{C}} .
$$


At the second stage, the firms maximize their anticipated profits

$$
\begin{aligned}
\pi^{S} & =\frac{\left(1-\theta^{C}\right)\left(1-\theta^{C}+\theta^{S} \theta^{C}-\left(\theta^{S}\right)^{2}\right)}{\left(3-2 \theta^{C}-\theta^{S}+\theta^{S} \theta^{C}\right)^{2}}, \\
\pi^{C} & =\frac{\left(1-\theta^{C}\right)\left(1-\theta^{S}\right)^{2}}{\left(3-2 \theta^{C}-\theta^{S}+\theta^{S} \theta^{C}\right)^{2}}
\end{aligned}
$$

by the simultaneous choice of $\theta^{S}$ and $\theta^{C}$, respectively. From the first order conditions $\partial \pi^{i} / \partial \theta^{i}=0$ for $i \in\{S, C\}$, we derive the firms' best response functions

$$
\theta^{S}\left(\theta^{C}\right)=\frac{1}{3-\theta^{C}} \quad \text { and } \quad \theta^{C}\left(\theta^{S}\right)=\frac{1-\theta^{S}}{2-\theta^{S}} .
$$

Solving this system of equations yields $\theta^{S}=\theta^{C}=\theta^{S C}:=(3-\sqrt{5}) / 2 \approx$ 0.382. Although the two firms are not symmetric, both choose the same level of responsibility in equilibrium. Due to their differing objective functions, however, the firms produce different quantities of the good:

$$
q^{S}=\frac{1}{3\left(1-\theta^{S C}\right)+\left(\theta^{S C}\right)^{2}}=\frac{1}{2}>\frac{\sqrt{5}-1}{4}=\frac{1-\theta^{S C}}{3\left(1-\theta^{S C}\right)+\left(\theta^{S C}\right)^{2}}=q^{C} .
$$

Intuitively, because both $C_{i}$ and $C S$ are increasing and convex functions of the firm's own output, $C_{i}<C S$ implies that a marginal increase in output is, ceteris paribus, more valuable for the CSR firm than for the CO firm. Put differently, CSR offers a stronger commitment to increase output than CO. Consequently, the CSR firm also makes higher profits than the CO firm:

$$
\pi^{S}=\frac{\left(1-\theta^{S C}\right)^{2}}{\left[3\left(1-\theta^{S C}\right)+\left(\theta^{S C}\right)^{2}\right]^{2}}>\frac{\left(1-\theta^{S C}\right)^{3}}{\left[3\left(1-\theta^{S C}\right)+\left(\theta^{S C}\right)^{2}\right]^{2}}=\pi^{C} .
$$

\subsection{Competition between two CO firms}

Finally suppose that both firms have chosen $\mathrm{CO}$ as corporate culture at the first stage and each firm $i \in\{1,2\}$ has chosen its CO level $\theta_{i}^{C}$ at the second stage. At the third stage, firm $i$ chooses its output $q_{i}$ in order to maximize its objective function (2) for any given weight $\theta_{j}^{C}$ of the rival firm. From the first-order condition $\partial V_{i}^{C} / \partial q_{i}=0$ we derive firm $i$ 's best response:

$$
q_{i}\left(q_{j}\right)=\frac{1-q_{j}}{2-\theta_{i}^{C}} .
$$

Using the symmetry of firms, we compute the equilibrium quantity of firm $i \in\{1,2\}$ as a function of $\theta_{i}^{C}$ and $\theta_{j}^{C}$ :

$$
q_{i}=\frac{1-\theta_{j}^{C}}{3-2 \theta_{i}^{C}-2 \theta_{j}^{C}+\theta_{i}^{C} \theta_{j}^{C}} .
$$


At the second stage, each firm anticipates these quantities and the corresponding price and chooses the $\mathrm{CO}$ level $\theta_{i}^{C}$ in order to maximize the corresponding profit

$$
\pi_{i}=\frac{\left(1-\theta_{j}^{C}\right)\left(1-\theta_{i}^{C}-\theta_{j}^{C}+\theta_{i}^{C} \theta_{j}^{C}\right)}{\left(3-2 \theta_{i}^{C}-2 \theta_{j}^{C}+\theta_{i}^{C} \theta_{j}^{C}\right)^{2}} .
$$

The first-order condition $\partial \pi_{i} / \partial \theta_{i}^{C}=0$ yields the best response

$$
\theta_{i}^{C}\left(\theta_{j}^{C}\right)=\frac{1}{2-\theta_{j}^{C}}
$$

Again using the symmetry of firms, we compute the equilibrium weights on customer surplus $\theta_{i}^{C}=\theta^{C C}:=1$ as well as the corresponding quantities $q_{i}=q^{C C}:=1 / 2$ and profits $\pi_{i}=\pi^{C C}:=0$ for $i \in\{1,2\}$. With homogeneous goods, Cournot competition between two $\mathrm{CO}$ firms leads to the same efficient allocation as perfect competition, i.e. zero profits and maximum consumer surplus. ${ }^{1}$

\subsection{Choosing corporate culture: CSR or CO?}

Combining the results from the three scenarios, we now examine the firms' decisions on corporate culture in the first stage. The possible actions and the corresponding continuation payoffs are represented in Table 1. Obviously, CSR is a dominant action for both firms.

Firm 2

\begin{tabular}{|c|c|cc|rl|}
\cline { 2 - 6 } Firm 1 & \multicolumn{2}{|c|}{ CSR } & \multicolumn{2}{c|}{ CO } \\
\cline { 2 - 6 } & $\mathrm{CSR}$ & $\pi^{S S} \approx 0.0856$ & $\pi^{S S} \approx 0.0856$ & $\pi^{S} \approx 0.0955$ & $\pi^{C} \approx 0.0590$ \\
\cline { 2 - 5 } & $\mathrm{CO}$ & $\pi^{C} \approx 0.0590$ & $\pi^{S} \approx 0.0955$ & $\pi^{C C}=0$ & $\pi^{C C}=0$ \\
\cline { 2 - 5 }
\end{tabular}

Table 1: Normal form representation of the first stage decisions

Proposition 1 In the unique SPE of game $\Gamma$, both firms will choose CSR as their corporate culture, put positive weight $\theta^{S S}$ on consumer surplus, and produce output $q^{S S}$, thereby making positive profits $\pi^{S S}$.

As explained in Section 3.2, CSR provides a stronger commitment to large quantities than CO. Moreover, unlike a CO firm, a CSR firm does not only suffer from a rise in the rival's quantity due to decreasing price and profit, but also benefits from it due to increasing consumer surplus. Compared to

\footnotetext{
${ }^{1}$ The result is equivalent to the finding that $t^{*}=1 / 2$ for homogeneous goods $(\gamma=1)$ in the model of Königstein and Müller (2001).
} 
a CO firm, this makes a CSR firm react less aggressive to an increase in the rival's $\theta$, i.e. to a tougher commitment to large quantities by the rival. Indeed, as the respective reaction functions (3) and (4) show, CSR levels are strategic substitutes, whereas CO levels are strategic complements. As a result, competition with CSR is less severe than with CO and allows for positive profits.

\section{Discussion}

Comparing the strategic potential of CSR and $\mathrm{CO}$ as commitments to larger quantities in Cournot competition, we have shown that firms prefer to care for all consumers rather than for own customers only, choosing positive levels of CSR.

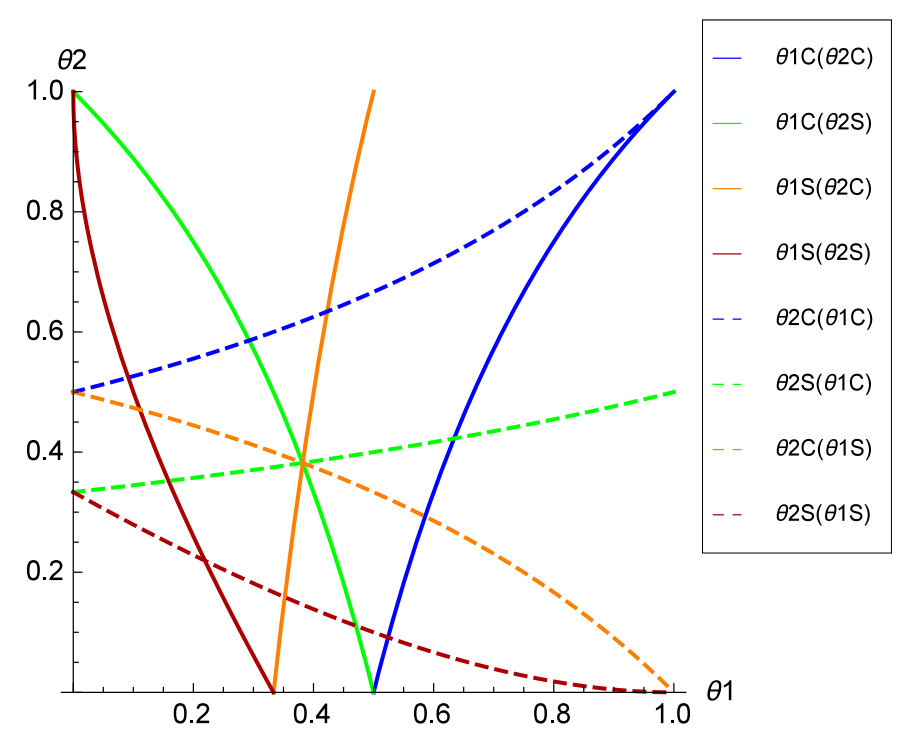

Figure 1: Best Response Correspondences

The result builds on our sequential set-up with three stages. Alternatively, we can consider a two-stage game in which the firms decide about their type of corporate culture and their level of commitment simultaneously in stage 1 , and about their output in stage 2 . For each choice $\theta_{j}^{k}, k \in\{S, C\}$ of his opponent $j$, player $i$ has then two best responses as depicted in Figure 1: CSR level $\theta_{i}^{S}\left(\theta_{j}^{k}\right)$ and CO level $\theta_{i}^{C}\left(\theta_{j}^{k}\right)$. The modified game thus has four SPE which are represented by the intersections of same-color best responses in Figure 1. The respective payoffs correspond to those given in Table 1. 
While none of the four equilibria is evolutionary stable under the indirect evolutionary approach ${ }^{2}$ the two symmetric ones are neutrally stable with the symmetric CSR equilibrium Pareto-dominating the symmetric CO equilibrium. Following this refinement strategy, the result that CSR outperforms $\mathrm{CO}$ is robust.

\section{References}

Deshpandé, R., Farley, J. U., and Webster, Jr., F. E. (1993). Corporate Culture, Customer Orientation, and Innovativeness in Japanese Firms: A Quadrad Analysis. Journal of Marketing, 57(January):1-18.

Fershtman, C. and Judd, K. L. (1987). Equilibrium incentives in oligopoly. American Economic Review, 77(5):927-940.

Goering, G. (2008). Socially concerned firms and the provision of durable goods. Economic Modelling, 25(3):575-583.

Güth, W. and Yaari, M. (1992). An evolutionary approach to explain reciprocal behavior in a simple strategic game. In Witt, U., editor, Explaning Process and Change - Approaches to Evolutionary Economics, pages 2334. University of Michigan Press, Ann Arbor.

Kitzmueller, M. and Shimshack, J. (2012). Economic Perspectives on Corporate Social Responsibility. Journal of Economic Literature, 50(1):51-84.

Königstein, M. and Müller, W. (2001). Why firms should care for customers. Economics Letters, 72(1):47-52.

Kopel, M., Lamantia, F., and Szidarovszky, F. (2014). Evolutionary competition in a mixed market with socially concerned firms. Journal of Economic Dynamics and Control, 48:394-409.

Planer-Friedrich, L. and Sahm, M. (2015). Strategic Corporate Social Responsibility. Mimeo, University of Bamberg.

\footnotetext{
${ }^{2}$ The indirect evolutionary approach has been introduced by Güth and Yaari (1992) and employed by Königstein and Müller (2001) in order to analyze competition between two CO firms.
} 